\title{
O QUE REVELA A PROVA BRASIL SOBRE SITUAÇÕES DE CONFLITOS EM ESCOLAS PÚBLICAS? CENÁRIOS DELINEADOS PELA VISÃO DE DOCENTES
}

\author{
WHAT DOES THE 'BRAZIL TEST' REVEAL ON CONFLICT SITUATIONS IN PUBLIC \\ SCHOOLS? THE SCENARIOS ARE OUTLINED BY FACULTY MEMBERS
}
LO QUE REVELA LA PRUEBA BRASIL SOBRE LAS SITUACIONES DE CONFLICTO EN LAS ESCUELAS PÚBLICAS? ESCENARIOS DESCRITOS POR MAESTROS

\section{Angela Maria Martins ${ }^{1}$ \\ Cristiane Machado ${ }^{2}$ \\ Maria Helena Bravo ${ }^{3}$}

\begin{abstract}
RESUMO: Este artigo tem como propósito cotejar o desempenho dos alunos na Prova Brasil com as respostas dos professores relativas à indisciplina e violência de escolas estaduais do município de Guarulhos, registradas nos questionários contextuais da mesma prova. Para este estudo, foram sistematizados os dados de 10 escolas que obtiveram alta pontuação no Ideb em 2007 e mantiveram esse crescimento em 2011; da mesma forma, foram sistematizados os dados de 10 escolas que obtiveram baixa pontuação no Ideb em 2007 e mantiveram tal tendência em 2011. Os dados foram cotejados com a sistematização das 29 questões sobre violência contidas na Prova Brasil, com vistas a identificar possíveis aproximações entre resultados de desempenho e situações de conflito e violência nas escolas. Conclui-se que há indícios de aproximações entre escolas com baixo desempenho no Ideb e o aumento de casos de conflitos escolares, porém, cabe destacar que os registros dessas situações aparecem mais em 2011 do que em 2007. Os dados analisados permitem afirmar ainda que há uma tendência de ampliação de níveis de intolerância recíproca entre alunos, professores e direção no espaço escolar, corroborando resultados de outros estudos que se dedicam a examinar o tema.
\end{abstract}

PALAVRAS-CHAVE: Prova Brasil. Avaliação externa. Conflitos escolares. Políticas educacionais.

\begin{abstract}
This article aims to put into perspective the performance of students in the Brazil Test with the teachers' responses to the indiscipline and violence of state schools in the municipality of Guarulhos, which are registered in the contextual questionnaires of the same test. For this study, data of 10 schools that achieved high scores in IDEB 2007 were organized and maintained this growth in 2011; likewise, data from 10 schools were systematized who obtained low scores in IDEB in 2007 and this trend continued in 2011. The data were compared with the systematization of 29 questions on violence contained in the Brazil Test, in order to identify possible similarities between performance results and situations of conflict and violence in schools. It was concluded that there is evidence of similarities between schools with low performance in IDEB and the increase

\footnotetext{
${ }^{1}$ Doutora em Educação, Professora da Universidade Cidade de São Paulo - SP - Brasil. Pesquisadora Sênior da Fundação Carlos Chagas - SP - Brasil - E-mail: ange.martins@uol.com.br.

${ }^{2}$ Doutora em Educação, Professora da Universidade Cidade de São Paulo - SP - Brasil. E-mail: cristiane13machado@yahoo.com.br.

${ }^{3}$ Pedagoga, Mestranda em Educação na Universidade de São Paulo - SP - Brasil. E-mail: mh.bravo@yahoo.com.br.
}

Recebido em: 21/05/2015 - Aprovado em: 21/10/2015. 
in cases of school conflicts; however, it is noteworthy that the records of these situations appear in greater volume in 2011 than in 2007. The analyzed data allow us to state that there is a trend in expansion of mutual intolerance levels among students, teachers and guidance at school, corroborating the results of other studies dedicated to examine the issue.

KEYWORDS: Brazil Test. External evaluation. School conflicts. Educational policies.

RESUMEN: Este artículo coteja el desempeño de los estudiantes en Prueba Brasil con las respuestas de los docentes acerca de la indisciplina y la violencia de las escuelas estatal es en el municipio de Guarulhos inscritas en los cuestionarios de contexto de la misma prueba. Para este estudio, se organizaron los datos 10 escuelas que lograron altos puntajes en Ideb en 2007 y mantuvieron este crecimiento en 2011; del mismo modo, se sistematizaron los datos de 10 escuelas que obtuvieron bajos puntajes en Ideb en 2007 y esta tendencia continuó en 2011. Los datos fueron comparados con la sistematización de 29 preguntas sobre la violencia que figuran en la Prueba Brasil, con el fin de identificar las posibles similitudes entre los resultados de rendimiento y las situaciones de conflicto y violencia en las escuelas. Llegamos a la conclusión de que hay pruebas de similitudes entre las escuelas con bajo rendimiento en Ideb y el aumento en los casos de conflictos de la escuela. Hay que destacar que los registros de estas situacion es aparecen en mayor volumen en 2011 que en 2007. Los datos permiten afirmar aunque hay una tendencia a la expansión de los niveles de intolerancia mutua entre los estudiantes, los profesores y la orientación en las escuelas, lo que corrobora los resultados de otros estudios dedicados a examinar la cuestión.

PALABRAS CLAVE: Prueba Brasil. Evaluación externa. Conflictos escolares. Políticas educativas.

\section{INTRODUÇÃO}

Inicialmente é preciso contextualizar a análise apresentada neste texto. Trata-se de resultados obtidos em projeto de pesquisa, desdobramento de investigação maior intitulada "Conflitos no espaço escolar: a gestão de escolas públicas em contextos vulneráveis" financiada pelo CNPq e pela Fundação Carlos Chagas -, que analisa os motivos pelos quais escolas públicas da rede de ensino estadual paulista, localizadas em regiões consideradas vulneráveis pela Secretaria de Estado da Educação de São Paulo (Seesp), aderem ao Programa Sistema de Proteção Escolar (SPEC), criado em 2009 e implantado por meio da Resolução SE 19, de 12/2/2010 (SÃO PAULO, 2010a).

O estudo original tem como propósito, de um lado, analisar o escopo legal e normativo do referido programa e atas de registros de ocorrências em unidades escolares da rede estadual de ensino; de outro lado, busca identificar e compreender as percepções de diretores escolares, professores mediadores comunitários e alunos que se relacionam nesses contextos sobre situações de conflito e violência. Parte-se do pressuposto que no cotidiano escolar e nas relações que se estabelecem entre diferentes atores escolares, instituem-se processos de (re)leitura ou de (re)interpretação do conjunto normativo e legal, preconizado por órgãos centrais, particularmente no que se refere ao Sistema de Proteção Escolar (SPEC).

Situações de conflito e violência que conturbam o ambiente escolar geram tensões de variadas ordens e a literatura da área tem apontado as dificuldades enfrentadas por parte dos profissionais da educação para enfrentar esses desafios, tomar decisões e agir (SPOSITO, GONÇALVES, 2002; CHARLOT, 2002; ABRAMOVAY, RUA, 2002; AQUINO, SAYÃO, 
2004; AQUINO, 1998; 1999; CARDIA, 1999; DEBARBIEUX, BLAYA, 2002; MINAYO, 1999; GOMES, MARTINS, 2014).

Tais dificuldades estariam na base das razões pelas quais as escolas tenderiam a buscar apoio externo para lidar com situações de conflito e violência, o que justificaria sua adesão ao Sistema de Proteção Escolar no estado de São Paulo. Este fenômeno chama a atenção pela rápida ampliação do referido Programa na rede estadual de ensino, entre 2010 a 2014 (GOMES, MARTINS, 2014). Tal ampliação indica tendências a serem examinadas com maior acuidade, destacando-se o fato de diretores terem desafios cada vez mais presentes em seu cotidiano de trabalho e precisarem enfrentá-los diante da ampliação de ocorrências de conflito e violência nas escolas, aderindo a um Programa de governo que se propõe a subsidiá-los nesse processo. Em outros termos, ao que tudo indica, as escolas não estão conseguindo administrar problemas sociais trazidos por alunos e suas famílias quando essas estão em uma condição classificada de vulnerabilidade social e que, na percepção escolar, repercutem nas relações escolares.

O Sistema de Proteção Escolar preconiza que as escolas podem contar com até dois docentes, para o desempenho das atribuições do Professor Mediador Escolar e Comunitário (PMEC), escolhido por meio da instrução conjunta CENP/DRHU de 9/4/2010 (SÃO PAULO, 2010b). Os critérios estabelecidos incluem o preenchimento de uma manifestação de interesse da escola em contar com o docente para exercer as funções de PMEC, a classificação dos candidatos e a atribuição de aulas.

Entretanto, os motivos que levam escolas públicas estaduais paulistas a aderirem ao programa são diversificados, conforme constatam Gomes, Martins (2014), pois as escolas prioritárias (que não conseguiram alcançar a meta estabelecida no Idesp - Índice de Desenvolvimento da Educação de São Paulo) têm primazia na seleção do PMEC e somente contam com um segundo PMEC quando funcionam em três turnos, com um mínimo de 10 (dez) classes em cada turno (SÃO PAULO, 2010b) ${ }^{4}$.

Tomando por base esse contexto geral, a investigação maior se propôs a desvelar as percepções de diretores, professores mediadores comunitários e alunos sobre as questões que envolvem situações de conflito e violência. Contudo, observou-se que outros dados seriam necessários com vistas a ampliar o escopo de análise e a visão desses problemas - o que nos levou a levantar, processar e sistematizar as respostas dos professores da rede estadual de ensino do município de Guarulhos nos questionários contextuais da Prova Brasil sobre questões de violência ${ }^{5}$.

Nesse sentido, é preciso assinalar que, embora os dados das avaliações externas não permitam outras leituras para além das respostas registradas no banco do Inep - Instituto

\footnotetext{
${ }^{4} \mathrm{Na}$ investigação maior, referida anteriormente, os diretores indicam que a sobrecarga de trabalho dos Professores Mediadores Comunitários é um desafio permanente no cotidiano das escolas que possuem o Sistema de Proteção Escolar.

${ }^{5} \mathrm{O}$ estudo intitulado "O que revela a Prova Brasil sobre situações de conflitos em escolas públicas? Cenários delineados pela visão de docentes" é coordenado por Cristiane Machado e dele participam Angela Maria Martins e Maria Helena Bravo.
} 
Nacional de Estudos e Pesquisas, as informações coletadas configuram o contexto mais amplo para o aprofundamento da análise sobre questões de violência em escolas públicas.

\section{A AVALIAÇÃO NACIONAL DO RENDIMENTO ESCOLAR}

A Avaliação Nacional do Rendimento Escolar (Anresc), mais conhecida como Prova Brasil, foi criada pelo Governo Federal em 2005 para, juntamente com a Avaliação Nacional da Educação Básica (Aneb), compor o Sistema de Avaliação do Rendimento Escolar (Saeb), existente desde 1990. As duas avaliações estimam o desempenho dos estudantes emprovas padronizadas de língua portuguesa e matemática, com ênfase em leitura e resolução de problemas. A principal diferença entre elas é que, enquanto a Aneb utiliza dados amostrais, a Anresc, ou Prova Brasil, afere o desempenho dos estudantes de $5^{\circ}$ e $9^{\circ}$ anos do Ensino Fundamental de forma censitária.

Essa expansão do contingente avaliação pelo Saeb representou um aumento significativo nos dados e informações disponíveis em todos os níveis, ampliando consideravelmente as possibilidades de análises e diagnósticos sobre a educação nacional. Bonamino e Sousa (2012, p. 379) destacam que no primeiro ano de aferição da Prova Brasil foram avaliados mais de 3 milhões de alunos, em aproximadamente 45 mil escolas urbanas de 5.398 municípios, enquanto o Saeb avaliou em torno de 300 mil alunos.

Além de avaliar o desempenho dos alunos em provas padronizadas, a Prova Brasil também coleta,de forma censitária,outras informações sobre a educação nacional por meio de questionários contextuais que são respondidos por alunos, diretores e professores, além de um questionário sobre a escola, preenchido nela mesma pelo aplicador da prova.Todos possuem questões de múltipla escolha e tentam captar as condições e infraestrutura das escolas e a percepção dos profissionais da educação sobre diversas dimensões que compõem o cotidiano escolar e educacional.

O objetivo desse levantamento, descrito no sítio eletrônico do Inep, órgão responsável pela aplicação das avaliações nacionais, é "fundamental para que a análise da Anresc (Prova Brasil) possa levar em consideração o contexto dos alunos e da escola. Uma das possibilidades a partir destes dados é o desenvolvimento de estudos dos fatores associados ao desempenho dos alunos" (BRASIL, 2015).

Este estudo, com base nos dados da Prova Brasil, pretende cotejar o desempenho dos alunos do $9^{\circ}$ ano do Ensino Fundamental com as respostas de professores de língua portuguesa e matemática de escolas estaduais do município de Guarulhos, relativas à indisciplina e violência registradas nos questionários contextuais da Prova Brasil, objetivando identificar possíveis aproximações entre essas duas informações.

Ainda que os dados obtidos em avaliações externas tenham limites no que diz respeito à compreensão dessas situações - abordadas cada vez mais por estudiosos e pela mídia -, 
cabe registrar a relevância de se desenhar o contexto mais amplo no qual os atores escolares se relacionam no seu cotidiano de trabalho.

É possível identificar convergência de ideias na literatura da área no que se refere à ausência de preparação adequada de professores e gestores para enfrentar situações de conflito que podem redundar em violência verbal e física. Nos anos de 1980, o foco dos estudos estava na discussão da questão da segurança nas escolas, envolvendo o patrimônio; nos anos de 1990 a análise apresentava como eixo as interações entre alunos ou destes com os adultos, culminando na elaboração do Estatuto da Criança e do Adolescente - ECA (LOPES, 2004). Gradativamente, o campo da análise se amplia para a compreensão da dinâmica escolar, tomando por base as interações entre professores, alunos, direção e pais. A partir da aprovação do ECA, as situações de conflito e violência envolvendo adolescentes e crianças passaram a ser amplamente divulgadas pela mídia.

Assinale-se também o sentimento de insegurança generalizado nas sociedades modernas, constituído por dinâmicas econômicas (oscilação na economia, desemprego, inflação); tecnológicos (acidentes ambientais, climáticos); saúde pública (novas epidemias). O cenário contemporâneo leva as pessoas a verem a violência em maior grau - em função da exposição midiática - em relação ao que efetivamente ocorre, fenômeno configurado pela autorreflexividade do indivíduo e das sociedades (MARTUCELLI, 1999).

Nesses termos, as situações de conflito e violência que ocorrem nos espaços escolares podem ser vistas a partir de múltiplos fatores, sobretudo em função das especificidades/singularidades das escolas, o que implica levar em consideração: os contextos nos quais estão localizadas (famílias e demais membros da comunidade); a dinâmica de organização e funcionamento pedagógico e administrativo (o papel das equipes de gestão e do corpo docente e administrativo); demandas configuradas pelo escopo normativo de órgãos centrais (programas e projetos de governo que institucionalizam a mediação de situações de conflito); fatores socioeconômicos e culturais.

Assim, a discussão centrada nas relações de ensino e de aprendizagem - com foco nos aspectos que dificultam a permanência de alunos no fluxo dos sistemas e redes - vem cedendo espaço para a necessidade de compreensão das relações mais amplas entre os diferentes atores que se relacionam em escolas públicas. Como dito anteriormente, as unidades de ensino precisariam se preparar para enfrentar contextos adversos, pois são inúmeras as dificuldades para implementar posturas mais adequadas no enfrentamento de conflitos, geralmente oriundos de situações não resolvidas entre professores, alunos, equipes de direção e pais, provocando (re) ações que podem chegar a agressões físicas (CANDAU, 2008; CECCON et al., 2009). 


\section{PROCEDIMENTOS METODOLÓGICOS}

Os instrumentos que compõem a Prova Brasil estão disponibilizados no sítio do Inep e o acesso aos modelos de provas e questionários pode ser feito com os recursos disponíveis nas ferramentas do Word do computador. Para obter as respostas aos questionários contextuais é necessário, contudo, recorrer aos microdados da Prova Brasil, que oferecem, para além destes, também os resultados dos testes de língua portuguesa e matemática.

Cabe observar que, apesar da indicação do Inep de que os dados coletados "poderão ser utilizados tanto por pesquisadores quanto por gestores municipais, estaduais e federais para estudos que subsidiem a melhoria da educação em todo o país" (BRASIL, 2015), não é isso que se depara ao tentar acessar os dados. Identificou-se uma não padronização no banco de dados do Inep, o que nos levou a utilizar distintos métodos de filtragem, tomando como critério principal o código de identificação do município. Para tratamento dessas respostas utilizou-se o software IBM SPSS (Statistical Package for the Social Science), programa especialmente desenvolvido para realizar análises estatísticas.

Inicialmente, o foco de análise seriam as respostas dos professores aos questionários dos anos de 2007, 2009 e 2011. No entanto, verificou-se um erro de processamento dos dados no que se refere à numeração das questões sobre indisciplina e violência no ano de 2009. Nestas, deveria-se indicar o tipo de agressão sofrida no ambiente escolar por um determinado ator (professor, aluno ou funcionário) e o sujeito dessa agressão (professor, aluno ou funcionário), o que contabilizaria 18 (dezoito) questões distintas. Entretanto, foram identificadas na sistematização feita pelo Inep, em 2009, como apenas 6 (seis) questões, inviabilizando o uso das respostas para compor a análise aqui proposta, tendo em vista a divergência no processamento dos dados. Dessa forma, optou-se por considerar apenas as respostas dadas pelos professores aos questionários dos anos de 2007 e 2011, para não comprometer a análise.

Para este estudo foram selecionadas 29 das 131 perguntas do questionário contextual da Prova Brasil de 2007, e 29 das 152 questões da aferição de 2011 referentes à temática da indisciplina e da violência. Concomitantemente, foram sistematizados os dados de 10 escolas que obtiveram alta pontuação no Ideb - Índice de Desenvolvimento da Educação Básica em 2007 e mantiveram este crescimento em 2011; e de 10 escolas que obtiveram baixa pontuação no Ideb em 2007 e mantiveram tal tendência em 2011. Doravante serão denominadas grupo A e grupo B, respectivamente. 
QUADRO 1- Escolas grupo A e pontuação no Ideb

\begin{tabular}{|l|c|c|}
\hline \multicolumn{1}{|c|}{ Escolas } & Ideb 2007 & Ideb 2011 \\
\hline Prof. Paulo Nogueira & 5,0 & 5,2 \\
\hline Crispiniano Conselheiro & 4,8 & 5,2 \\
\hline Jose Alves de Cerqueira Cesar & 4,6 & 5,0 \\
\hline Deputado Jose Storopoli & 4,6 & 4,8 \\
\hline Vereador Antonio de Re & 4,5 & 5,1 \\
\hline Erico Verissimo & 4,5 & 4,8 \\
\hline Prefeito Rinaldo Poli & 4,2 & 4,5 \\
\hline Profa Maria Aparecida Felix Aorto & 4,2 & 4,4 \\
\hline Prof Frederico de Barros Brotero & 4,1 & 5,1 \\
\hline Vereador Elisio de Oliveira Neves & 4,1 & 4,7 \\
\hline
\end{tabular}

Fonte: MEC/INEP, 2015.

QUADRO 2- Escolas do grupo B e pontuação no Ideb

\begin{tabular}{|l|c|c|}
\hline \multicolumn{1}{|c|}{ Escolas } & Ideb 2007 & Ideb 2011 \\
\hline Pedro Morceli & 3,6 & 3,4 \\
\hline Valdivino de Castro Pereira & 3,5 & 3,2 \\
\hline Prof.Licinio Carpinelli & 3,5 & 3,4 \\
\hline Prof. Mario Bombassei Filho & 3,5 & 2,9 \\
\hline Lydia Kitz Moreira & 3,5 & 3,2 \\
\hline Inocoop II & 3,5 & 3,2 \\
\hline Bartholomeu de Carlos & 3,4 & 3,3 \\
\hline Conj Hab Bairro dos Pimentas II & 3,2 & 2,9 \\
\hline Profa Therezinha Closa Eleuterio & 3,1 & 2,7 \\
\hline Parque Primavera & 3,0 & 2,5 \\
\hline
\end{tabular}

Fonte: MEC/INEP, 2015

Nas Escolas do grupo A, no ano de 2007, 93 professores responderam ao questionário da Prova Brasil; no ano de 2011 esse número foi de 111 professores. No grupo B, em 2007, 112 responderam ao questionário e 123 em 2011. As informações obtidas nessas duas sistematizações foram cotejadas com o objetivo de verificar possibilidades de estabelecer aproximações (ou não) entre elas.

Destaca-se o fato do questionário contextual ser um instrumento com questões fechadas de múltipla escolha, não permitindo outras leituras acerca do tema em pauta para além das respostas registradas no bando de dados do Inep. Contudo, os dados analisados indicam tendências e questões emergentes, possibilitando - no escopo da investigação referida anteriormente - o aprofundamento da discussão por meio de procedimentos qualitativos (instrumentos semi-estruturados e dinâmicas de grupo), com 42 diretores e 52 Professores Mediadores Comunitários da rede estadual do município de Guarulhos. 


\section{PROVA BRASIL E O REGISTRO DOS PROFESSORES SOBRE INDISCIPLINA E VIOLÊNCIA NA ESCOLA}

Guarulhos, um dos 39 municípios da Grande São Paulo, segundo o IBGE (2015), tem uma população estimada em 2014 de 1.312.197 habitantes, o que a torna a segunda cidade com maior população do Estado de São Paulo e a $12^{\mathrm{a}}$ mais populosa do Brasil. Distante apenas $17 \mathrm{~km}$ da capital, o município encontra-se estrategicamente localizado na confluência de estradas que ligam São Paulo ao Rio de Janeiro, abrigando também o maior aeroporto da América Latina, no qual está o maior terminal de cargas do país. Tais características transformaram a cidade em um centro estratégico de distribuição e logística, com uma produção que representa mais de $1 \%$ do Produto Interno Bruto (PIB).

A rede estadual de ensino de Guarulhos, segundo dados do Censo Escolar de 2014, conta com um total de 111.940 matrículas no Ensino Fundamental e 5.415 funções docentes para a mesma etapa. A rede abarca 175 escolas, das quais 169 oferecem Ensino Fundamental regular.

No ano de 2007 o questionário contextual da Prova Brasil foi respondido por 93 professores de língua portuguesa e matemática dos nonos anos do Ensino Fundamental do grupo A e em 2011 esse número foi de 111 professores. Nas escolas do grupo B, em 2007, 112 professores responderam ao questionário eem 2011esse número foi de 123 professores. Em 2007 o questionário contextual continha 131 questões, sendo 29 relativas à temática da indisciplina e da violência; em 2011 o total de questões foi de 152 e, também, 29 se referiam ao tema estudado.

Problemas disciplinares causados por alunos são uma dificuldade recorrente no cotidiano das escolas estaduais de Guarulhos selecionadas nesta amostra, de acordo com as respostas dos professores. No grupo A, no ano de 2007, 84 professores $(90,4 \%)$ do total de 93 respondentes, afirmaram terem ocorrido conflitos dessa ordem no espaço escolar. Em 2011, 76 professores entre os 111 que responderam ao questionário (77,5\%) assinalaram a ocorrência de problemas disciplinares causados por alunos, contingente menor do que em 2007; no entanto, 15 respostas (13,5\%) foram perdidas, enquanto em 2007 nenhum professor ficou sem responder essa questão. No grupo B, no ano de 2007, 92 professores $(82,2 \%)$ do total de 112 respondentes, afirmaram terem ocorrido conflitos dessa ordem no espaço escolar. Em 2011, 83 professores entre os 123 que responderam ao questionário $(67,4 \%)$ assinalaram a ocorrência de problemas disciplinares causados por alunos, contingente menor do que em 2007; no entanto, houve um aumento considerável nas respostas que afirmam terem sido problemas graves, de 16 professores (14,3\%) em 2007 o número saltou para 34 (27,6\%) em 2011.

Destaca-se, aqui, um dos limites do questionário examinado. Pela sua configuração não é possível identificar a que se referem os professores quando apontam problemas disciplinares causados pelos alunos, muito menos o que seriam os casos considerados graves. No entanto, chama a atenção o aumento de $13,3 \%$ nos relatos de problemas disciplinares 
graves, configurando-se importante indicativo para a análise das relações que se estabelecem no espaço escolar. Quando se observam as respostas às questões referentes às agressões verbais perpetradas pelos alunos no espaço escolar temos as seguintes ocorrências:

QUADRO 3 - Respostas referentes a agressões verbais de alunos nas escolas da amostra

\begin{tabular}{|l|c|c|c|c|}
\hline AGREDIDOS & Grupo A - 2007 & Grupo A - 2011 & Grupo B - 2007 & Grupo B - 2011 \\
\hline Professores & $71(76,3 \%)$ & $66(59,5 \%)$ & $75(67 \%)$ & $79(64,2 \%)$ \\
\hline Funcionários & $31(33,3 \%)$ & $49(44,1 \%)$ & $37(33 \%)$ & $69(56,1 \%)$ \\
\hline Alunos & $57(61,3 \%)$ & $61(55 \%)$ & $59(52,7 \%)$ & $72(58,5 \%)$ \\
\hline
\end{tabular}

Fonte: MEC/INEP, 2015. Dados processados pelas autoras.

Verifica-se um aumento da agressão verbal de alunos contra funcionários nos dois grupos de escolas de 2007 para 2011, sendo que no grupo B esse aumento foi maior do que no grupo A, 23,1\% naquele contra $10,8 \%$ neste. No entanto, nos dois grupos, a agressão contra professores recuou, sendo que no grupo A o recuo foi de $16,8 \%$, bem superior ao grupo B que recuou somente em 2,8\%.

Contudo, quando observados os números de agressões de professores e funcionários das escolas contra os alunos, uma significativa alteração é constatada. Evidencia-se uma ampliação, de 2007 para 2011, nos casos das agressões verbais contra alunos por parte de professores e funcionários nos dois grupos de escolas, conforme quadro a seguir:

QUADRO 4 - Respostas referentes a agressões verbais de funcionários e professores a alunos nas escolas da amostra

\begin{tabular}{|l|c|c|c|c|}
\hline AGRESSORES & Grupo A - 2007 & Grupo A - 2011 & Grupo B - 2007 & Grupo B - 2011 \\
\hline Professores & $4(4,3 \%)$ & $20(18 \%)$ & $5(4,5 \%)$ & $22(17,9 \%)$ \\
\hline Funcionários & $6(6,5 \%)$ & $160(14,4 \%)$ & $2(1,8 \%)$ & $8(6,5 \%)$ \\
\hline
\end{tabular}

Fonte: MEC/INEP, 2015. Dados processados pelas autoras.

Em relação à agressão física, quando o agressor é o aluno, as respostas dos professores aos questionários indicam as seguintes ocorrências:

QUADRO 5 - Respostas referentes a agressões físicas de alunos das escolas da amostra

\begin{tabular}{|l|c|c|c|c|}
\hline \multicolumn{1}{|c|}{ AGREDIDOS } & Grupo A - 2007 & Grupo A - 2011 & Grupo B - 2007 & Grupo B - 2011 \\
\hline Professores & $10(10,8 \%)$ & $10(9 \%)$ & $3(2,7 \%)$ & $29(23,6 \%)$ \\
\hline Funcionários & $3(3,2 \%)$ & $6(5,4 \%)$ & $1(0,9 \%)$ & $17(13,8 \%)$ \\
\hline Alunos & $44(47,3 \%)$ & $43(38,7 \%)$ & $55(49,1 \%)$ & $55(44,7 \%)$ \\
& & & & \\
\hline
\end{tabular}

Fonte: MEC/INEP, 2015. Dados processados pelas autoras. 
Neste caso, nota-se redução das ocorrências de agressão física entre alunos nos dois grupos de escolas, enquanto os casos contra professores e funcionários aparecem com uma ampliação significativa, especialmente no grupo B que apresenta, respectivamente, aumento de 2007 para 2011 de 20,9\% e 12,9\%. Os questionários, ainda, indagaram os professores sobre fatos que ocorreram dentro das salas de aulas, enquanto ministravam suas aulas conforme descrição abaixo- temos as seguintes situações:

QUADRO 6 - Respostas referentes a situações de conflito em sala de aula

\begin{tabular}{|l|c|c|c|c|}
\hline \multicolumn{1}{|c|}{ SITUAÇÕES } & $\begin{array}{c}\text { Grupo A } \\
\mathbf{2 0 0 7}\end{array}$ & $\begin{array}{c}\text { Grupo A } \\
\mathbf{2 0 1 1}\end{array}$ & $\begin{array}{c}\text { Grupo B } \\
\mathbf{2 0 0 7}\end{array}$ & $\begin{array}{c}\text { Grupo B } \\
\mathbf{2 0 1 1}\end{array}$ \\
\hline Ameaça por aluno & $12(12,9 \%)$ & $13(11,7 \%)$ & $9(8 \%)$ & $23(18,7 \%)$ \\
\hline Agressão verbal por aluno & $48(51,6 \%)$ & $25(22,5 \%)$ & $37(33 \%)$ & $53(43,1 \%)$ \\
\hline $\begin{array}{l}\text { Alunos frequentaram aulas } \\
\text { sob efeito de bebida alcoólica }\end{array}$ & $11(11,8 \%)$ & $12(10,8 \%)$ & $22(19,6 \%)$ & $22(17,9 \%)$ \\
\hline $\begin{array}{l}\text { Alunos frequentaram aulas } \\
\text { sob efeito de drogas ilícitas }\end{array}$ & $13(14 \%)$ & $22(19,8 \%)$ & $25(22,3 \%)$ & $47(38,2 \%)$ \\
\hline $\begin{array}{l}\text { Alunos frequentaram aulas } \\
\text { portando arma branca }\end{array}$ & $4(4,3 \%)$ & $0(0 \%)$ & $10(8,9 \%)$ & $14(11,4 \%)$ \\
\hline $\begin{array}{l}\text { Alunos frequentaram aulas } \\
\text { portando arma de fogo }\end{array}$ & $0(0 \%)$ & $0(0 \%)$ & $0(0 \%)$ & $8(6,5 \%)$ \\
\hline
\end{tabular}

Fonte: MEC/INEP, 2015. Dados processados pelas autoras.

Nesses registros chama a atenção o aumento de tais situações, com exceção do possível uso de bebida alcoólica para frequência às aulas, ocorrido em 2011 no grupo B das escolas. A ampliação de alunos que frequentaram as aulas sob o efeito de drogas ilícitas foi de $15,9 \%$, portando arma branca de $2,5 \%$ e portando arma de fogo, que era imperceptível em 2007, de 6,5\%. Há, aqui, uma indicação explícita de aumento de situações de violência das escolas, principalmente, no ano de 2011 nas escolas do grupo B. Em se tratando do grupo de alunos analisados, -adolescentes com média de 14 anos, que é o universo de estudantes do último ano do Ensino Fundamental - os dados merecem atenção especial e aprofundamento na discussão sobre dinâmicas escolares que permitam à escola o enfrentamento dessas situações.

\section{CONSIDERAÇÕES}

O propósito do estudo foi o de cotejar o desempenho dos alunos do $9^{\circ}$ ano do Ensino Fundamental com as respostas de professores de língua portuguesa e matemática de escolas estaduais do município de Guarulhos relativas à indisciplina e violência registradas nos questionários contextuais da Prova Brasil. Para tanto, foram sistematizados dados de 10 escolas que obtiveram alta pontuação no Ideb em 2007 e mantiveram esse crescimento em 
2011; e dados de 10 escolas que obtiveram baixa pontuação no Ideb em 2007 e mantiveram essa tendência em 2011. Em um segundo momento, foram sistematizadas as respostas dos professores dessas escolas e, após esse levantamento, esses dados foram cotejados.

Os dados permitem verificar que as mudanças nas respostas em relação aos anos de 2007 e 2011 são significativas, principalmente nos dados das escolas do grupo B. Os registros de ocorrência de problemas disciplinares graves causados por alunos saltaram de 14,3\% (16 professores) para 27,6\% (34 professores). Houve aumento considerável das ocorrências de agressão verbal de alunos contra funcionários, de 23,1\%. O mesmo pode-se perceber em relação às ocorrências de agressão física de alunos contra professores e funcionários, que ampliou em 20,9\% e 12,9\%, respectivamente.Situações com potencial para resultar em conflito em sala de aula foram da ordem de $15,9 \%$, no caso de alunos que frequentaram as aulas sob o efeito de drogas ilícitas, de 2,5\% portando arma branca e de 6,5\% portando arma de fogo, ocorrência não registrada na aferição anterior estudada. Pode-se ressaltar aqui, uma indicação explícita de aumento de situações de violência em escolas, principalmente, no ano de 2011, nas escolas do grupo B.

Entretanto, chama a atenção o registro das respostas de professores sobre agressões verbais de professores/funcionários a alunos, que aumentaram nos dois grupos de escolas estudados. No grupo A, o aumento dos casos de agressão verbal de professores contra alunos foi de 4,3\% para $18 \%$ (de 4registros para 20) e no grupo B foi de 4,5\% a 17,9\% (de 5 a 22 registros). No caso de agressão de funcionários a alunos, no grupo A ampliou de 6,5\% para $14,4 \%$ (de 6 para 16 registros) e, no grupo B, de 1,8\% para 6,5\% (de 2 para 8 registros).

Esse movimento pode indicar que há uma tendência de ampliação de níveis de intolerância (recíproca?) entre os diferentes atores que atuam no espaço escolar. Como espaço institucional onde convivem atores sociais oriundos de diferentes segmentos e portadores de identidades constituídas a partir de trajetórias de vida completamente diversas do ponto de vista econômico, cultural e social, as escolas são permeadas por situações de conflito e violência a serem examinadas com base em suas peculiaridades. Sendo ponto de encontro de crianças e de adolescentes, os espaços educativos retratam a realidade de uma sociedade atualmente marcada pela cultura da intolerância. Para superar esse fenômeno, seria desejável que os conflitos fossem "bem manejados" (Ceccon et alli, 2009, p. 19), e não vistos como positivos ou negativos, mas como possibilidade de criação de novas atitudes e de aprendizagem institucional, no que diz respeito à gestão de escolas.

Entretanto, é preciso assinalar que a configuração de situações de conflito e violência nas unidades escolares não é recente e vem crescendo gradativamente. As políticas educacionais implementadas, sobretudo desde os anos de 1980, ampliaram a cobertura e o atendimento da educação básica, o que possibilitou o ingresso de amplos segmentos da população de classes menos favorecidas economicamente. Todavia, as redes e sistemas de ensino lidam com dificuldades no que tange ao revigoramento dos processos de ensino e de aprendizagem - que deveriam considerar as características sociais, econômicas e culturais desses segmentos - o que pode ter contribuído para potencializar situações de conflito e/ou de violência simbólica e física nos espaços escolares. 
Porém, reorganizações pedagógicas e administrativas para dinamizar práticas profissionais inadequadas podem gerar (re) ações mais contraditórias do que aquelas que deram origem ao processo. Essa dinâmica pode fazer com que o professor/gestor/funcionário da escola, portanto, adulto responsável naquela situação, coloque-se em condição de igualdade às crianças e adolescentes. Nesse sentido, bom senso aliado à formação adequada para mediar situações de conflito, configuram elementos fundamentais para evitar que se chegue a agressões físicas no espaço escolar (AQUINO, 1999).

Os dados coletados e analisados neste texto ratificam outros estudos realizados em torno do tema. O Sindicato dos Professores do Ensino Oficial do Estado de São Paulo (Apeoesp) realizou, durante o XXI Congresso da entidade em dezembro de 2006, pesquisa sobre violência com 700 professores-delegados ${ }^{6}$. Os profissionais indicaram os tipos mais comuns de violência, sendo que a verbal foi a mais citada, com $96 \%$ dos casos; os atos de vandalismo aparecem em segundo lugar, com 88,5\% das dos casos, seguido da agressão física e do furto, com $82 \%$ e $76 \%$ dos casos, respectivamente. Os casos mais graves, como os de roubo ou assalto a mão armada foram mencionados por $18 \%$ dos delegados, de violência sexual por $9 \%$ e de assassinato por $7 \%$.

Ao serem questionados se haviam visto armas no interior da escola, 20\% deles afirmaram ter presenciado armas de fogo e nenhum deles mencionou ter visto a posse de arma branca. A entidade também assinala outros tipos de violência que podem ser classificadas como incivilidades, sendo que essas manifestações partem de alunos e pais de alunos: $77 \%$ dos professores já foram xingados por alunos; $23 \%$ afirmam que os insultos são frequentes e $54 \%$ afirmam que eles ocorrem raramente. Com relação aos pais, a porcentagem é menor, mas significativa: 27,5\% dos professores afirmaram que já foram ameaçados, xingados ou agredidos por esses. No que tange a manifestações da violência ligadas à discriminação, as respostas indicam menções isoladas ou ligadas a questões sexuais, de raça e gênero: em torno de $22 \%$ dos professores afirmaram já ter sofrido algum tipo de discriminação dessa natureza. A pesquisa também indica que a maior parte dos casos de violência é provocada ou infligida por alunos (cerca de $93 \%$ dos casos). Embora pouco significativo, há indicação de pais e responsáveis como protagonistas em situações de violência, assim como professores e diretores.

Acrescente-se que a literatura da área vem sublinhando que as tecnologias de informação - por meio das redes sociais - possibilitam ao aluno a divulgação de ofensas a colegas, professores e famílias. Essas atitudes poderiam ser trabalhadas nos currículos escolares a fim de orientar as crianças e os adolescentes para a prática de uma internet segura, baseada no respeito ao outro, e não apenas na implantação de bloqueadores de sites, medida que, isoladamente, não resolve o problema. O bullying, outra forma rotineira de violência no ambiente das unidades escolares, tem preocupado as equipes gestoras e os pais, pois práticas de bullying são constantemente divulgadas por meio de recursos virtuais ocasionando uma exposição da vítima, colocando-a em situação pública (OLIBONI, 2008).

\footnotetext{
${ }^{6}$ Disponível em: <http://www.apeoesp.org.br/hotsite/observatorio/abertura.html>. Acesso em 12/05/2014.
} 
Como se disse anteriormente, não é possível identificar - por meio da Prova Brasil as percepções de professores sobre a violência quando respondem aos itens do questionário, pois o termo é polissêmico e pode abranger desde agressões graves até pequenos atos de incivilidades. Assim, não é de todo improvável que o aumento das situações registradas esteja relacionado à estigmatização de comportamentos comuns a adolescentes no ambiente escolar, levando à sua criminalização e consequente judicialização das situações. A literatura que examina o comportamento de adolescentes nas relações escolares vem sublinhando o choque de gerações, de valores sociais e normas de conduta, processo que não é recente nas redes e sistemas de ensino, mas que tem se ampliado no cenário social adverso permeado por relações supérfluas, esvaziadas de significado. Assim, é preciso assinalar que as situações de violência somente podem ser analisadas em determinados contextos, cujas particularidades devem ser levadas em consideração.

É preciso identificar fatores externos e internos que contribuem para o agravamento da violência nos espaços escolares. Entre os primeiros, podem ser apontadas as questões de gênero e étnico-raciais; os processos migratórios; a estrutura familiar; a influência da mídia; o contexto econômico, social e cultural no qual a escola está inserida. No que diz respeito aos fatores internos, podem ser assinalados: idade e nível de escolaridade dos alunos; dificuldade de escolas para lidar com regras e estabelecer uma disciplina nas relações cotidianas; processos de ensino e de aprendizagem que não conseguem mobilizar o interesse dos alunos ou que lhes possibilite construir expectativas de futuro; quebra na relação de autoridade entre professores e alunos ${ }^{7}$.

Por fim, como se disse anteriormente, o ambiente escolar é permeado por relações entre os diferentes atores marcadas por conflitos que podem ir de discussões até chegar a agressões verbais e físicas. Cardia (1999), ao desenvolver um estudo sobre o tema, assinala que, além dos professores, os próprios alunos se queixam da falta de controle e de limites no espaço escolar, o que indica ausência de regras claras na convivência cotidiana. O pluralismo de normas (ou sua ausência) confunde a todos no que tange aos limites a serem respeitados e à construção da noção do que seria uma boa conduta no espaço escolar.

Assim, pode-se perguntar: Até onde os pequenos atos de rebeldia, de resistência - de alunos que não "gostam" da aula de terminados professores e/ou de professores que não acatam as orientações das equipes de direção - acabam por configurar um caldo cultural que pode explodir em situações de violência física? Porém, questões como essa exigem os aprofundamentos necessários com vistas a desvelar percepções dos atores escolares envolvidos nessas situações.

\footnotetext{
${ }^{7}$ Ver o estudo de Abramovay, Rua (2002).
} 


\section{REFERÊNCIAS}

ABRAMOWAY, Miriam; RUA, Maria das Graças. Violência nas escolas. Brasília, DF: UNESCO, 2002.

AQUINO, Julio Groppa. A indisciplina e a escola atual. Revista Faculdade de Educação, São Paulo, SP, vol. 24, n. 2, p. 181-204. jul./dez. 1998. Disponível em: <http://goo.gl/9q2OMS>. Acesso em: 21 mai. 2015. ISSN 0102-2555.

AQUINO, Julio Groppa; SAYÃO, Rosely. Em defesa da escola. São Paulo: Papirus, 2004.

AQUINO, Julio Groppa. Indisciplina na escola: alternativas teóricas e práticas. São Paulo: Summus, 1999.

BRASIL. Ministério da Educação. Instituto Nacional de Estudos e Pesquisas. Questionários contextuais. Disponível em: 〈http://goo.gl/4Odzia〉. Acesso em: 05 mar. 2015.

BONAMINO, Alícia Catalano; SOUSA, Sandra Zákia Lian de. Três gerações de avaliação da educação básica no Brasil: interfaces com o currículo da/na escola. Educação e Pesquisa, São Paulo, SP, v. 38, n. 2, p. 373-388. abr./jun. 2012. Disponível em: <http://goo.gl/HrNu4F>. Acesso em: 21 mai. 2015. ISSN 1517-9702.

CANDAU, Vera Maria Ferrão. Direitos humanos, violência e cotidiano escolar. In:

CANDAU, Vera Maria Ferrão. (Org.). Reinventar a escola. 5.ed. Petrópolis: Vozes, 2008.

CHARLOT, Bernard. A violência na escola: como sociólogos franceses abordam essa questão. Sociologias, Porto Alegre, RS, n. 8, p. 432-443. jul./dez. 2002. Disponível em: <http://goo.gl/VzbESS >. Acesso em: 21 mai. 2015. ISSN 1807-0337.

CARDIA, Nancy. Pesquisa sobre atitudes, normas culturais e valores em relação à violência em 10 capitais brasileiras. Brasília: Ministério da Justiça, Secretaria de Estado dos Direitos Humanos, 1999.

CECCON, Claudia et alli. Conflitos na escola: modos de transformação: dicas para refletir e exemplos de como lidar. São Paulo: CECIP: Imprensa Oficial do Estado de São Paulo, 2009.

DEBARBIEUX, Eric; BLAYA, Catherine (Org.). Violência nas escolas e políticas públicas. Brasília, DF: UNESCO, 2002.

GOMES, Roberto Alves; MARTINS, Angela Maria. A normatização do sistema de proteção escolar em São Paulo: situações de conflitos no espaço escolar. Revista @ mbienteeducação, São Paulo, SP, vol. 7, n. 2, p. 230-242. mai./ago. 2014. Disponível em: <http://goo.gl/ldyr8P>. Acesso em: 14 abr. 2015. ISSN 1982-8632.

IBGE. Instituto Brasileiro de Geografia e Estatística. Disponível em: 〈http://goo.gl/lU7bhH $\rangle$. Acesso em: 05 mar. 2015. 
LOPES, Rosilene Beatriz. Significações de violências na perspectiva de professores que trabalham em escolas "violentas". 2004. 157 f. Dissertação (Mestrado em Educação) Universidade Católica de Brasília, Brasília, DF, 2004.

MARTUCCELLI, Danilo. Reflexões sobre a violência na condição moderna. Tempo Social, Revista de Sociologia, São Paulo, SP, n. 1, p. 157-175. mai. 1999. Disponível em: <http://goo.gl/nsgwCz>. Acesso em: 21 mai. 2015. ISSN 1809-4554.

MINAYO, Maria Cecília de Souza. et al. Fala galera: juventude, violência e cidadania na Cidade do Rio de Janeiro. Rio de Janeiro: Garamond, 1999.

OLIBONI, Samara Pereira. O bullying como violência velada: a percepção e ação dos professores. 2008. 109 f. Dissertação (Mestrado em Educação Ambiental) - Universidade Federal do Rio Grande. Rio Grande: UFRG, 2008.

SÃO PAULO (Estado). Secretaria de Estado da Educação. Resolução SE n. 19, de 12 fev. 2010. Institui o Sistema de Proteção Escolar na rede estadual de ensino de São Paulo e dá providências correlatas. São Paulo, CENP/DRHU, 2010a.

SÃO PAULO (Estado). Secretaria de Estado da Educação. Instrução Conjunta CENP/DRHU de 09 abr. 2010. À vista da publicação da Resolução SE n. 19, em 12 fev. 2010, que institui o Sistema de Proteção Escolar na rede estadual de ensino paulista, e considerando a necessidade de orientar as autoridades educacionais quando aos procedimentos a serem adotados pela Diretoria de Ensino para a seleção das unidades escolares que contarão com docentes para o exercício das atribuições de Professor Mediador Escolar e Comunitário, expedem a presente instrução. São Paulo, SP: CENP/DRHU, 2010 b.

SPOSITO, Marilia Pontes; GONÇALVES, Luis Alberto Oliveira. Iniciativas públicas de redução de violência escolar no Brasil. Cadernos de Pesquisa, São Paulo, SP, n. 115, p. 101138. mar. 2002. Disponível em: 〈http://goo.gl/JnjX9j〉. Acesso em: 21 mai. 2015.

ISSN 1980-5314.

Como citar este documento:

MARTINS, Ângela Maria; MACHADO, Cristiane; BRAVO, Maria Helena. O que revela a Prova Brasil sobre situações de conflitos em escolas públicas? Cenários delineados pela visão de docentes. ETD - Educação Temática Digital, Campinas, SP, v. 17, n. 3, p.x-xx, set./dez. 2015. ISSN 1676-2592. Disponível em: <http://periodicos.sbu.unicamp.br/ojs/index.php/etd/article/view/8635363>. Acesso em: 11 dez. 2015. 